\title{
Implementing a mentor support system for general practice nurse mentors
}

\author{
Anthony Chambers, Debra Smith and Lisa Billingham
}

\begin{abstract}
The development of the Advanced Training Practice (ATP) scheme in general practice (GP) has led to an increase in placement provision for pre-registration student nurses to experience the unique opportunities general practice provides to nurse all ages and demographic groups across all fields of nursing. The rise in numbers of trained mentors in practices attached to the ATP hub has led to an increase in the number of student nurses on placement in the GP clinical environment. Adequate support for mentors in individual GP practices across the ATP scheme is essential. This article will explore how a mentorship support system was developed in the ATP hub and has enabled mentors to provide highquality mentorship that student nurses need. We discuss the features that have made this support successful and the considerations for other ATP practices to implement a similar support system that demonstrates the ongoing commitment to and recognition of the value mentorship brings to the GP practice setting.
\end{abstract}

\section{Keywords: mentorship practice nursing support ATP}

\section{Introduction}

Mentorship is a vital and mandatory aspect of the assessment of pre-registration nursing students in the UK (Walsh 2014, Nursing and Midwifery Council (NMC) 2008). Students spend $50 \%$ of their time in practice placements and these placements are pivotal to the training and education of pre-registration nurses. There is an abundance of literature about the important role mentors have in developing and training the future nursing workforce, assessing students' performance in practice, and acting as professional role-models. However, evidence shows that mentors face barriers to mentor effectively and provide the 
required input that successful mentoring requires and students deserve (Price 2007, Boast 2015). The development and introduction of mentor meetings for general practice nurses has enabled the Advanced Training Practice (ATP) hub to provide the mentors with a forum to discuss their concerns, share their experiences and problem solve issues about mentoring. In turn this has given the ATP hub a platform to maintain their live mentor register through mentor updates, coordinate timely educational audits and provide a robust mentor support system.

\section{Background}

Practice nursing has become a key role in general practice with nurses taking on more clinical responsibilities, and as more traditional hospital services may be provided in GP primary care settings in the future, general practice will require more nurses to choose this area of nursing to cope with these increasing demands.

The ATP scheme is an initiative funded by Health Education England (HEE) which aims to address these demands by developing the training infrastructure in primary care and securing the future primary care workforce. The scheme focuses on increasing the number of placements in general practice for pre-registration nursing students and promoting practice nursing as a career pathway when in the past it might have been overlooked by student nurses. Facilitating placements for pre-registration nursing students in general practice is essential to attracting nurses into practice nursing and changing assumptions that practice nursing has limited career progression opportunities (Lane and Peake 2015).

The ATP model was introduced by HEE as a Yorkshire-wide project in 2009 and developed locally by the Haxby Group. The ATP scheme infrastructure is organised with one main GP practice acting as the 'hub' with other local practices receiving support as 'spokes'.

In 2013 the ATP scheme evolved to become the mainstream strategy for the Yorkshire and Humber region (Box 1). 


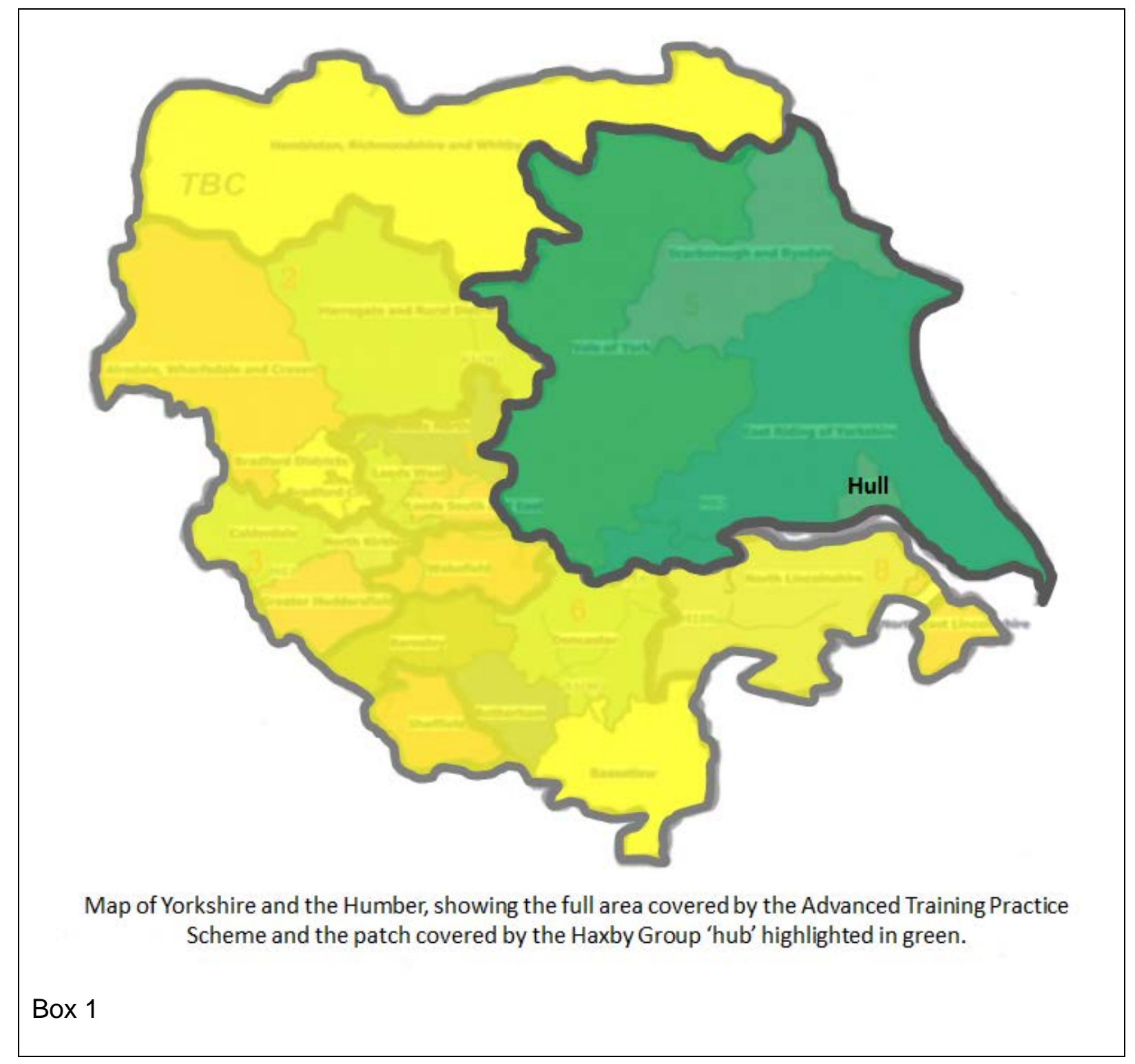

During this period there has been increased investment in staff training and professional development which includes mentorship. Across the local ATP patch the number of mentors has increased from only 1 mentor at the start of the project to over 70 mentors in 2016 . In total, the local ATP hub and spokes provided 65 student placements in 2015 and this year it is expecting 100 pre-registration student nurses to have full GP placements. In addition to these placements, practices also regularly take students for one/two day taster visits.

The ATP scheme has an emphasis on nurse education and the inclusion of nurse mentors enriches the clinical learning environment of each placement practice by promoting multiprofessional learning with a range of clinical practice opportunities (Gale et al 2016). The 
skills of mentorship mapped to the Standards for Learning and Assessment in Practice (NMC 2008) provides quality assurance which sees mentorship as an integral part of the success of the ATP model for the education, teaching and training of its staff and students. ATP student evaluations show that mentorship is of an extremely high standard in general practice (Lane and Peake 2015). The NMC mentor standards are a key aspect of the success of the education of student nurses to the extent that attending an NMC approved mentorship course is one of the training requirements in the ATP scheme for newly recruited practice nurses. Locally, the GP practices have benefitted from this investment as the ATP has successfully recruited 22 students post-qualification and trained them as practice nurses some of whom are now mentors themselves. The very first Haxby Group (Hull) ATP student is now a nurse team leader in Hull and another is starting on the Advanced Nurse Practitioner (ANP) pathway.

\section{The value of mentorship in general practice}

GP practice placements provide unique opportunities for student nurses to learn and develop new, transferable skills and knowledge in a range of clinical expertise that can be experienced in general practice (Bradby and McCallum 2015): vaccinations, chronic disease management, wound care, and ECGs being only a few. Students in ATP placements with practice nurses will have one-to-one mentoring which has a positive impact on student learning and confidence (Baglin and Rugg 2010). This further reinforces the culture of high quality educational support in a multi-professional environment while developing student nurses' knowledge and skills and preparing them for a possible career in GP practice nursing (Gale et al 2016).

Studies indicate the value of GP clinical placements to both students - who gain a greater sense of autonomy and confidence, and practice nurses - who gain an opportunity to update their own skills via teaching and supporting students (Gale et al 2016, RCN 2015, Myall et al 2008). From these various studies we have identified some recurring concepts of the 
benefits of mentorship for practice nurses and we have summarised these into seven themes in Table 1. Analysing the literature helped us in providing the focus for the ATP mentor support meetings so that these themes are covered in the meetings.

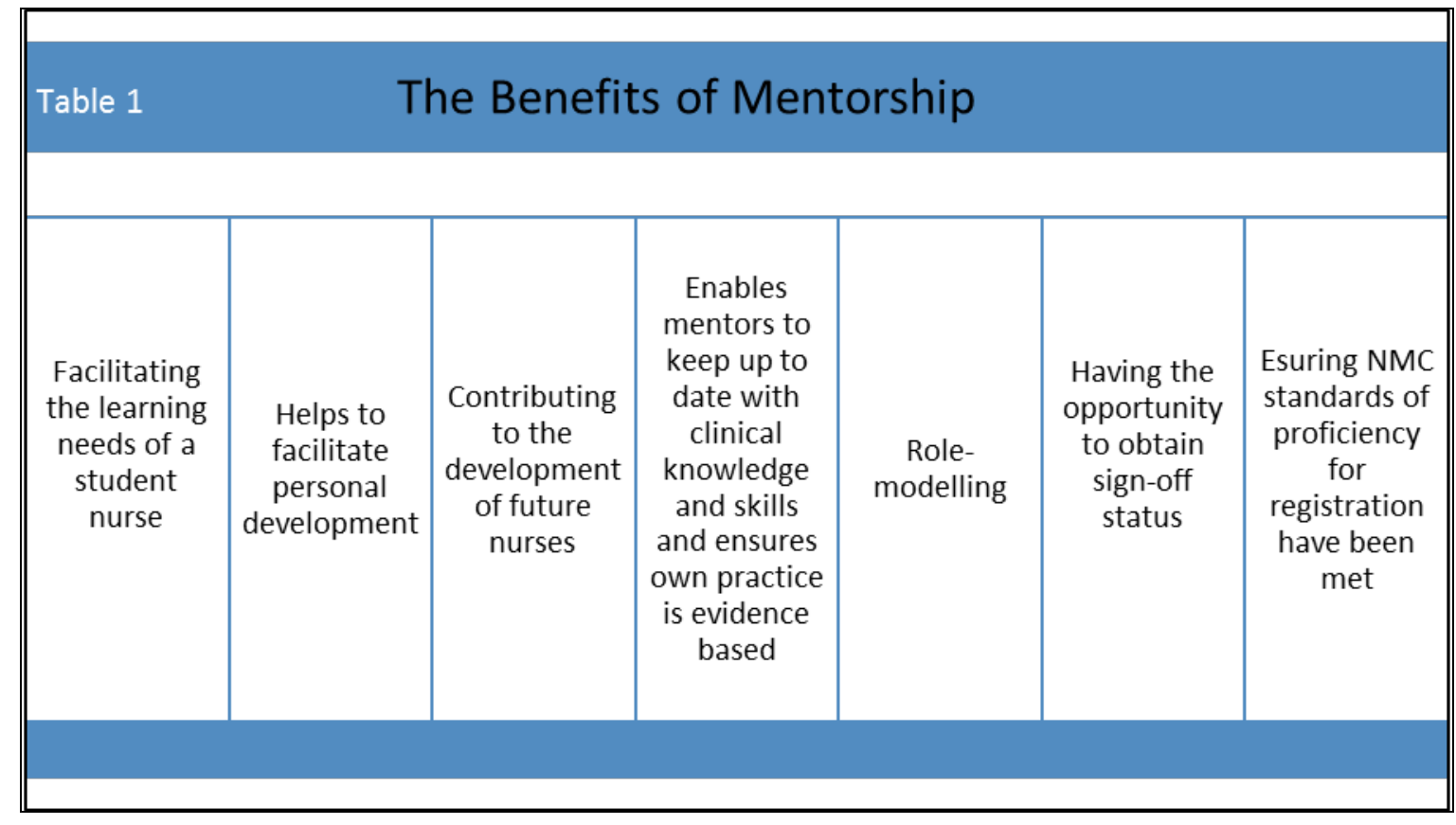

\section{The challenges of mentorship in general practice}

Mentoring can add additional pressures to clinical workloads and mentors themselves frequently refer to barriers that they need to overcome (Veeramah 2012, O'Driscoll et al 2010). These barriers which can affect the quality of mentoring include lack of time, timed clinical appointment systems, conflict between the competing demands of being a mentor and providing patient care and a lack of support from both their employer and the $\mathrm{HEI}$ (Commission on Education and Training for Patient Safety 2016, Boast 2015, Willis Commission 2012, Myall et al 2008). Mentors also report having to deal with additional mentorship challenges and responsibilities which include; dealing with students who are having difficulties in achieving required competencies and managing poor student performance (Robinson et al 2012). These findings are reinforced from feedback we receive from practice nurses mentors who tell us about the lack of time they have to thoroughly mentor, support and assess students while performing their main clinical duties. Despite 
organisations having agreements through the Learning and Development Agreement (LDA) (HEE 2014) that mentors will have dedicated time for mentorship, protected time to mentor is often not possible, particularly in GP placements (Boast 2015). Robinson et al (2012) found that as well these demands on their time, mentors face further difficulties in meeting ongoing mentorship development needs. Other studies have found that mentors want support from their manger and the $\mathrm{HEl}$ including increased time for attending mentor updates and greater flexibility in how and where the update is delivered (Pulsford et al 2002).

This need for mentors to be supported, and therefore provide high-quality mentorship that students require, was the driver behind the ATP initiative to have regular mentor meetings. The meetings guarantee the mentors in the hub and spokes protected time to fulfil their role for updates and training, and provide the support they need from managers and the HEI.

\section{Support network}

If mentorship is seen as key to the ATP ethos of quality assured educational learning environments for nursing students, then support for the practice nurses delivering the practice-based learning is essential to ensure the mentors remain up-to-date and motivated with this important role. Although there is wide variety in the level of support for practice nurses from their GP employers which includes their mentorship role (Bradby and McCallum 2015, Corbett and Bent 2005), practice nurses themselves recognise that support for mentorship is essential (Bradby and McCallum 2015). Providing support to the mentors and allowing them time for mentorship is necessary so that they can undertake their role effectively and have the opportunity to attend mentor updates and complete triennial reviews. The development of our mentor support scheme was based around this supportive ethos and we see this investment as invaluable to motivate, inspire and promote good mentorship skills and meet the professional standards for mentorship. We have identified key areas of support which are required by mentors and have ensured the continued 
success of practice nurse mentorship in the ATP. These key areas are the link lecturer and the practice learning educator from the local HEI and the training team in the ATP hub.

The challenges that mentors face can be reduced through a supportive manager and an environment that supports learning (Leinster 2009). The ATP hub has a lead nurse mentor and a training team to manage the student allocations and coordinate placements across the hub and spokes. They also work in partnership with the HEI to monitor and ensure the quality of the placements. This includes: maintaining the ATP mentor register, coordinating placement audits, and liaising with the HEI about student and mentor issues. The support from the hub ensures that mentors are prepared for the students' arrival while allowing the mentor to continue with their clinical role. To address the issue of lack of time, the ATP practices factor protected time for mentors to ensure that the three interviews that student nurses have on each placement can be undertaken.

To support practice learning the HEI has a practice learning educator and a link lecturer, who provide educational, and student and mentor support in the ATP hub and spokes. Locally there has been a tradition of a mentor support network through the practice learning facilitator (PLF) role. The PLF role has always been viewed as essential to the promotion and maintenance of high quality mentorship standards, enabling resolution of placement, student and mentor issues as well as being responsible for maintaining the local mentor register and assisting with student allocations. To ensure equity of mentor support in the sectors identified as PIVOs (private, independent and voluntary organisations) a similar supportive role, a practice learning educator (PLE), exists to support mentors. This PLE role is essential to the maintenance of mentorship standards in the ATP scheme by providing a link between the ATP mentors and the HEl and ensuring that mentors have the required information and resources to facilitate student learning and assessment effectively.

The link lecturer is also an effective channel of support to the ATP hub and spoke mentors by providing educational support for student related problems that are impacting on their 
ability to perform in practice. While the link lecturer role has been criticised (Sharples et al 2007) it has an important and established part in supporting learning in practice (Macintosh 2015). The link lecturer compliments and enhances the PLE role by acting as a further link for communication and partnership between practice and education.

This collaborative provision of mentorship support to the hub and spokes meets the NMC (2008) requirements that mentors have access to a support network. The development of our mentor meetings has strengthened the links between the ATP practices and the HEI. The collaborative working with the local ATP lead nurse mentor has enabled the HEI to have a regular and active presence in the ATP hub and spokes to support the mentors.

\section{Implementation of the support}

The lead nurse mentor in the ATP hub started the mentor meetings to develop a support network for all of the mentors in the hub and spokes. The meetings provided a forum for mentors in the ATP scheme to share experiences and problem solve mentorship issues, and develop networking links with other mentors. Collaborative working between the PLE and the ATP hub gave the PLE an opportunity to build on these established meetings and exploit their potential to use them to facilitate a mentorship update. As well as enabling mentor updates to be held the PLE involvement has allowed for a greater variety of mentor related topics to be explored at the meetings, ranging from revalidation to student assessment documentation and facilitation of difficult to achieve practice learning standards.

A SWOT analysis was undertaken to determine the success of the meetings as well as highlight potential challenges to the meetings so that the meetings could be improved. The SWOT findings are summarised in table 2 . 


\begin{tabular}{|c|c|}
\hline $\begin{aligned} & \text { Strengths } \\
&> \text { Forum to share ideas } \\
&> \text { Maintain live mentor } \\
& \text { status } \\
&> \text { Networking } \\
&> \text { Quarterly to minimise } \\
& \text { effect on clinical } \\
& \text { duties } \\
&> \text { Facilitation of mentor } \\
& \text { update }\end{aligned}$ & $\begin{array}{l}\text { Weaknesses } \\
\quad>\text { Effect on clinic } \\
\text { appointments } \\
>\begin{array}{l}\text { Release from clinical } \\
\text { duties }\end{array}\end{array}$ \\
\hline $\begin{array}{l}\text { Opportunities } \\
\quad>\text { Mentors to request } \\
\text { topics } \\
>\text { Localised meetings to } \\
\text { maximise attendance, } \\
\text { reduce travel }\end{array}$ & $\begin{array}{l}\text { Threats } \\
\qquad \begin{array}{ll} \\
\quad \text { Large geographical } \\
& \text { area } \\
> & \text { Increased travel times }\end{array}\end{array}$ \\
\hline
\end{tabular}

Initially the meetings were quite small but as the number of mentors in the hub and spokes have increased the size and scope of the meetings has also grown. The main effect of this has been to incorporate the mentor update into the meeting. We now have quarterly meetings with a large attendance in both Hull and York. To address mentors' concerns about increased travel times, additional meetings will be established in other geographical locations to maximise attendance and maintain engagement with mentors across the whole ATP geographical area.

Meetings are chaired by the ATP lead nurse mentor and minutes are taken to enable dissemination and allow the ATP hub to have a record of actions needed about mentorship issues. Dates for the next meeting are set at each meeting so that the mentors can plan their diaries and clinics around the meetings and the ATP hub send out reminders and the agenda 1-2 weeks by group email before the meeting. Mentors are asked at each meeting to identify topics for discussion for the next meeting. This avoids meetings having the same content every time and prevents mentors feeling they had wasted their time attending or that the meetings are not relevant to their own experiences or concerns. All mentors receive a copy of the minutes of the meeting which is recognised as an important part of the information flow as it will contain useful information and links to resources. Both the PLE 
and the link lecturer attend and contribute to the meetings which reinforce and maintain $\mathrm{HEI}$ links with the ATP practices and allows facilitation of the mentor update that meets NMC requirements (Table 3 ).

\begin{tabular}{|l|l|}
\hline \multicolumn{2}{|c|}{ Table 3 NMC requirements for mentor update } \\
\hline $\begin{array}{l}\text { An opportunity to meet and } \\
\text { explore assessment and } \\
\text { supervision issues with other } \\
\text { mentors. }\end{array}$ & $\begin{array}{l}\text { Explored as a group activity } \\
\text { the validity and reliability of } \\
\text { judgements made when } \\
\text { assessing practice in } \\
\text { challenging circumstances. }\end{array}$ \\
\hline \\
(NMC 2008 p12)
\end{tabular}

The meetings have taken a variety of delivery styles from interactive workshops to the sharing of case studies around pertinent student issues. Meetings are set for two hours and strict time-keeping is essential to ensure maximum use of the time available and to finish on time to allow staff to resume clinical duties. Mentors' concerns are recorded confidentially and, where immediate resolution is not possible, this enables action plans to be created to resolve issues. Although the meetings are structured there is sufficient flexibility in their delivery to ensure the needs of the attending mentors are met. Each session ends with mentors being invited to ask questions of the PLE and link lecturer. This enables individual mentor concerns to be raised and, where possible, solutions offered to resolve the issues which supports collaborative learning and promotes innovative practice.

\section{Recommendations for practice}

For meetings like ours to be successful we recommend that the following considerations are addressed:

- They must be interactive where mentors can participate in a confidential supportive environment.

- Ideally they need to be held in locations which are accessible for all mentors even if this means holding more meetings in a variety of locations. 
- Consideration must be given to resources such as adequate room size and refreshment facilities.

- They should maintain and promote partnership working with the HEI by including HEI representation and the meetings should be developed to include a mentor update that meets NMC requirements.

This has undoubtedly been one of the strengths of the meetings and has enabled mentors to maintain their live mentorship status and the ATP hub to keep the mentor register up-to-date and ensure that the meetings target those who are in need of an update.

\section{Conclusion}

General practice placements for pre-registration student nurses in the ATP scheme are an innovative strategy that provides high quality teaching in a positive learning environment where dedicated time for learning is valued and successful learning experiences for students are a priority. Mentors are the key personnel in facilitating this and effective mentorship is crucial to produce nurses who are fit for practice. To be successful, the practice nurse mentors require support if they are to meet the NMC (2008) standards for learning and assessment in practice. A collaborative supportive environment provided by the $\mathrm{HEI}$ and the ATP for mentors that acknowledges and takes into account the competing demands on their time as well as being a mentor is not only important but is a necessary component of mentorship (Winterman et al 2014). Without a supportive environment for the mentors to operate in or where they are under-prepared for their responsibilities as mentors, they will struggle to carry out their mentor role (O'Driscoll et al 2010). Mentors need protected time away from clinical duties to support and assess students and to attend regular mentor updates. Supporting mentors to mentor is crucial in retaining mentors on the live register, providing an optimum learning environment and ensuring the continued viability of the clinical area as a placement for pre-registration student nurses (Winterman et al 2014). The support network of mentor meetings discussed here has the characteristics of a good 
practice learning environment advocated by the Willis Commission (2012) and can provide the necessary support to implement the NMC (2008) standards and ensures that the public is protected through the registration of safe and competent nurses.

\section{References}

Baglin M, Rugg S (2010) Student nurses' experiences of community-based practice placement learning: A qualitative exploration. Nurse Education in Practice. 10(3), 144-152.

Boast G (2015) Highlighting the value of mentoring students in general practice. Practice Nursing. 26(11), 560-563.

Bradby M, McCallum C (eds) (2015) General Practice Nursing in the 21st Century A Time Of Opportunity. London: Queens Nursing Institute.

Commission on Education and Training for Patient Safety (2016) Improving Safety Through $\begin{array}{llll}\text { Education and } & \text { Training. Available at }\end{array}$ https://hee.nhs.uk/sites/default/files/documents/FULL\%20report\%20medium\%20res \%20for\%20web.pdf [Accessed 05 July 2016].

Corbett K, Bent S (2005) Developing clinical placements for nursing students in general practice: a survey of the views of practice nurses. Education for Primary Care. 16: 167-174.

Gale J, Ooms A, Sharples K, Marks-Maran D (2016) The experiences of student nurses on placements with practice nurses: a pilot study. Nurse Education in Practice. 16(2016), 225-234.

Goldman E, Plack M, Roche C, Smith J, Turley C (2009) Learning in a chaotic environment. Journal of workplace learning. 21(7), 555-574. 
Gopee N (2105) Mentoring and Supervision in Healthcare. $3^{\text {rd }}$ edition. London: Sage.

Health Education England (HEE) (21014) Schedule C: Quality Assurance and Performance Management https://hee.nhs.uk/sites/default/files/documents/Scedule-C-QualityAssurance-and-Performance-Management.pdf $\quad$ [Accessed 5 July 2016].

Lane P, Peake C (2015) A scheme to increase practice nurse numbers. Nursing Times. 111(13), 22-25.

Leinster S (2009) Learning in the clinical environment. Medical Teacher. 31, 79-81.

MacIntosh T (2015) The link lecturer role; inconsistent and incongruent realities. Nurse Education Today. 35(2015), 8-13.

Myall M, Levett-Jones T, Lathlean J (2008) Mentorship in contemporary practice: the experiences of nursing students and practice mentors. Journal of Clinical Nursing. $17,1834-1842$.

Nursing and Midwifery Council (2008) Standards to support learning and assessment in practice: NMC standards for mentors, practice teachers and teachers. $2^{\text {nd }}$ Edition. London: Nursing and Midwifery Council.

O'Driscoll M, Allan H, Smith P (2010) 'Still looking for leadership - who is responsible for student nurses' learning in practice?' Nurse Education Today. 30(3), 212-217.

Price B (2007) Practice-based assessment: strategies for mentors. Nursing Standard. 21(36), 49-56.

Pulsford D, Boit K, Owen S (2002) Are mentors ready to make a difference? A survey of mentors' attitudes towards nurse education. Nurse Education Today. 22(6), 439-446.

Robinson S, Cornish J, Driscoll C, Knutton S, Corben V, Stevenson T (2012) Sustaining and managing the delivery of student nurse mentorship: roles, resources, standards and 
debates. Report for the NHS London 'Readiness for Work' programme. London: National Nursing Research Unit, King's College.

Royal College of Nursing (2015) RCN Mentorship Project 2015: From today's support in practice to tomorrow's vision for excellence. London: Royal College of Nursing.

Sharples K, Kelly D, Elcock K (2007) Supporting mentors in practice. Nursing Standard. 21(39), 44-47.

Veeramah V (2012) What are the barriers to good mentoring? Nursing Times. 108(39), 1215.

Walsh, D (2014) The nurse mentor's handbook: Supporting students in clinical practice. 2nd Edition. Maidenhead: Open University Press.

Willis Commission (2012) Quality with compassion: the future of nursing education. Report of the Willis Commission on Nursing Education. London: The Royal College of Nursing.

Winterman E, Sharp K, McNamara G, Hughes T, Brown J (2014) Support for mentors in clinical education. Nursing Times. 110(51), 21-23. 